\title{
comentario
}

\section{Las publicaciones oficiales en México}

Como en todo Estado moderno, en nuestro país encontramos una continua transferencia de información del gobier no ha cia el pú bli co a tra vés de di ver sos me dios. Uno de ellos, y qui zá el de ma yor trascen den cia,locons tituyen las publicaciones oficiales que han adquirido una importancia primordial, no sólo por la gran cantidad de temas que tratan sino porque constituyen un medio indispensable de información entre gobierno y gobernados, por que resca tan el pa tri mo nio cul tu ral del país y por que son fuen te in dis pen sable de con sul ta paraeles tu dio so, el investigador y el público en general.

Las publicaciones ofi ciales cons ti tu yen, portan to, una fuen te esen cial por su rique za y va rie dad de in for mación y en oca siones son la única fuen te para la rea li zación de in vesti gaciones so bre múl ti ples temas de estudio de nuestro país. Los go bier nos ma ne jan de ma ne ra ex clu si va mu chain for ma ción vi tal como son los cen sos de pobla ción, industriales, y económicos, así como estadísticas básicas sociales y económicas, datos sobre la distribución de in gre sos y egresos, etc. Ade más de los asun tos le gales, políti cos y ad mi nis trati vos, consideradostradicionalmente como oficiales, son diversos y muy amplios los asuntos de que se ocupan las publicaciones oficiales ya que com pren den des de el pro duc to de una in ves ti ga ción cien tífica has ta in forma ción so bre arte, his to ria, agricul tu ra, cocina, literatura, cur sos de cor te y con fec ción, etc., pre sen ta da en di fe ren tes formatos: libros, revistas, folletos, mapas, discos, videocassettes, microfichas y discos de computadora.

El Gobierno Federal puede ser considerado el editor más grande del país, y dado que sus publicaciones ofrecen una visión amplia del desarrollo social, económico, educativo y cultural de México, es necesario que éstas sean da das a co no cer en for ma or ga ni za da y efi cien te para que pue dan ser aprove cha das am plia men te por to dos los interesados.

Sin embargo, la ma yo ría de las de pen den cias ofi ciales no se preo cu pan de bi da men te por pla near la edición, difusión, distribución y conservación de sus publicaciones. De ahí que exista una carencia de información actual y sistematizada sobre la producción bibliográfica del gobierno mexicano que cada día es más vasta y compleja.

En 1973 se afir ma ba que: "El sec tor pú bli co me xi ca noca re ce de un sis te ma cohe ren te para la pro duc ción y dis tribución de sus publicaciones. A lo largo del tiempo, se han dado diversas soluciones parciales al problema, pero to da vía ocu rre que cada ins ti tu ción pú bli ca y, aún en mu chos ca sos, cada una de sus de pen den cias, man tienen sus propios sistemas editoriales, con criterios de estilo, de contenido y de formato propios, que además varían al cambiar de funcionarios. Esta atomización y falta de unidad, aunada a la ausencia de normas de control de calidad y de presupuestos, eleva los costos y propicia la confusión y la duplicidad en el trabajo. 